\title{
Nhimbe as a model for re-invigorating sustainable socio-economic development in Zimbabwe and Africa
}

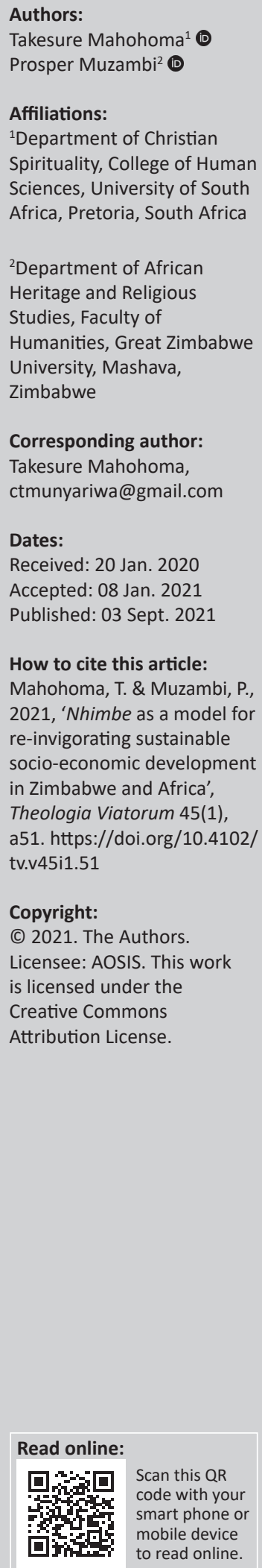

This research looks at the nhimbe activities in major areas of development, especially in the area of agriculture, politics, economics and religion. The article endeavours to show that the nhimbe as a traditional model can be used as a hinge for sustainable and integral development. It is also a source of livelihood that assures that everyone in the community is accommodated and taken care of. The Shona nhimbe concept is treated as a viable approach that is in line with a response to the September 2015 world leaders' resolutions that focused on sustainable development. It is argued in this research that the nhimbe philosophy can be used as a response to Goal 1 of the United Nations Development Programme (UNDP) for sustainable development that says 'No Poverty'. The study also identifies the state and communities as integral partners (Goal 17 on partnerships for the goals). The research further highlights the areas where communities and the state can cooperate to improve the lives of communities, thereby creating a responsible citizenry.

Keywords: nhimbe; collaborative ministry; sustainable community development; mushandirapamwe; economic development.

\section{Introduction}

The concept of nhimbe is a Shona cultural value which has a myriad of explanations. It is part of history and future. Its praxis is possible to attain the millennium development goals (MDGs). Nhimbe can be considered in these days of high competition for wealth accumulation where many are competing vigorously for a share in natural resources. Reflecting on co-operative engagement, this study will explore ways through which the Shona concept of nhimbe can be considered as a viable alternative or complementary ideology in fostering sustainable community development. The purpose of this research is to discuss the essence of nhimbe with its concomitants that can be used for sustainable economic development in both rural and urban Zimbabwe. In addition, Nhimbe carries economic, social, religious and political overtones. It can be translated into communal plans, performance and procedures for supporting one another in the community in order to achieve the desired objectives.

Our discussion apparently encourages all to be entrepreneurial through the government's blue print of Zimbabwe Agenda for Sustainable Socio-Economic Transformation (ZimAsset).

In dealing with this topic, in Zimbabwe, there are tribal concepts that are linked to nhimbe. Amongst them are Ndebele and Shangaans. The Ndebele call it ilima. There are other hybrid African terms that are akin to nhimbe like Ujamaa of Julius Kambarage Nyerere and Harambee of Mzee Jomo Kenyatta. These will be expounded later in our discussion. Nhimbe is a central alternative model that equips the poor and disadvantaged rural people who are being economically dominated by few elite rich people.

\section{Research methodology}

A qualitative research methodology was conducted based on the perceptions of the Shona people on nhimbe, jakwara or jangano. ${ }^{1}$ It portrays a community's resilience to hard work and togetherness. This is embedded in the local customs and their belief systems. Since most of it is undocumented, it relied on indigenous people in a locale. The quality and validity of knowledge were tested and refined through an adaptive process that includes hands-on experimentation and integration of knowledge into the social community proceedings. The interview questions were based on the living conditions of the rural Shona people in Chivi, Masvingo province, solutions to challenges

1.Jakwara and jangano are concepts closely linked to nhimbe. These concepts are elaborated on a section specifically dealing with nomenclature. 
that affect them daily and the different activities and outcomes of nhimbe. The advantages of this method are that the researcher obtains primary evidence from people concerned and is able to relate the data with insights from other Zimbabwe cultural groups like Ndebele and Shangaans.

The researcher faced challenges that include limited time because many people were still harvesting, and they were also busy with political meetings outlined for them. They managed to participate in only some nhimbes. Moreover, library data gathering was done. In other words, there are many books, articles, journals and websites which are available either supporting or opposing nhimbe. The researcher has had the privilege of reading many of these resources and attained surmountable knowledge on the subject under discussion.

\section{Background of research}

The Shona socio-economic fabric has always been based on the household that consists of different families. A family is the basic unit of production and consumption, although with cooperation of other family units (Beach 1995:20). This is why it is very rare for a Shona family to exist in isolation. The underlying fact in the economy and political development is the ideology of nhimbe for resources, religion, wealth and general welfare. In the past, each family took part in hunting, gathering of wild vegetables and fruits, the herding of cattle, mining and agricultural activities.

The basic economy of Shona is agriculture and cattle raring. The individual ownership of land involves collaboration of cultivating, sowing crops, ploughing, weeding and harvesting. Nhimbe is an integral part of the above-mentioned activities. Whenever a family is overwhelmed by extensive labour, a nhimbe is organised. As Daneel (1971) states:

Much beer (doro) is brewed for the occasion, because beer is a tangible form of compensation (not as payment in the strict sense of the word, but in recognition of the principle of reciprocity) given to the village members who offer their services on the appointed day. (p. 35)

\section{Nomenclature of nhimbe}

As a word, nhimbe involves a happy moment people enjoy when they work together, especially as a community, family or friends. It implies agreement, a bonding over something, a meeting of minds and a sign of oneness. It is a Shona traditional concept that runs deep in their culture. As Mawere and Awuah-Nyamekye (2015:12) state, '[ $t$ ]he word nhimbe comes from the Zimbabwean Shona language and culture'. It has a plethora of interpretations depending on the region and cultural practice. It can be loosely translated as community collaboration. Nhimbe creates a life spectrum of an atmosphere of enjoying and enjoining friendship and familial sentiments. According to some scholars like Ngara (2013), nhimbe is a traditional cooperation in the execution of household chores from agricultural to construction work. This is in agreement with Murisa (2013:251-290) who posits that the practice was developed within a family structure of social organisation where members of the same lineage group became organised into labour teams for ploughing, planting, weeding and other related field duties. Bourdillon (1976:74) concurs with this line of thought when he states, '[l]arger groups of kin may cooperate for larger tasks such as ploughing or reaping'. This practice is usually practised in rural communal areas. This practice strengthens the sense of belonging within the communities (Murisa 2013:251-290). Generally, nhimbe refers to residents in a community working together to help each other in daily life. Thus, a family can hire labour from neighbours. As Bourdillon (1976) puts it, nhimbe is:

A more traditional means of obtaining help, which is still the practice in some areas, is to hold a work party: the land-holder brews a quantity of millet beer and invites friends and neighbours to help with his work (which apart from agricultural work may involve such tasks as building or roofing a house) for which they can enjoy the beer, which lasts considerably longer than the work. (p. 74)

It is a practice that is known by different names amongst Shona ethnic groups. Some communities call it nhimbe, whilst others refer to it as humwe, jangano or jakwara. According to Tavuyanago, Mutami and Mbenene (2010:1-8), nhimbe is synonymous with jakwara or jangano. However, there is a thin line between nhimbe and jakwara or jangano. Mostly nhimbe is viewed as a beer party centred on work. Mawere and AwuahNyamekye (2015) contend that nhimbe is a Shona word, meaning 'to help one another'. In addition, the word nhimbe is embedded in the Shona cultural and anthropological belief system. It entails that people come and work together in order to achieve a common goal (Mawere \& Awuah-Nyamekye 2015:12). It is a socio-economic practice that is undertaken during ploughing, weeding and harvesting periods.

However, nhimbe is not limited to these. There are other forms of nhimbe that are realised at rituals and ceremonies that include marriage and funeral. For marriage, it is usually a practice amongst the Shona that roora rinoitwa muonera pamwe [marriage is a communal event] through kupemberera. Members of the same family make contributions in cash or kind when one of them pays lobola [bridal price]. The communal element is realised in that a sahwira [family friend] is called to play a mediatory role between the groom's and bride's families during the negotiating process of the lobola.

Furthermore, the nhimbe practice is realised at funeral rites of passage. When a member of a community dies, community members contribute by providing various forms of help from the moment of a member's death to the burial. The community pays chema [bereavement fund], collects mealie-meal and relish as a way of showing solidarity and oneness. Men will help erect a musasa [temporary shelter] and help dig the grave. Collaborative ministry is therefore realised amongst the Shona of Zimbabwe.

Generally, nhimbe entails people working together towards a common goal. It enables people from different villages to 
work together to uplift the condition of another person. As a result, it cuts down labour costs by enhancing efficiency and effectiveness. It has a powerful social effect through its interactive nature. Cooperation in a community is a prerequisite for the common good. Hence, it promotes the fundamental right of an individual. It is worth noting that this is still being practised in most areas within the Masvingo and Midlands provinces. Because of the scourge of human immunodeficiency virus and acquired immunodeficiency syndrome (HIV and AIDS) and massive exodus of energetic youth force to South Africa, neighbouring countries and elsewhere around the globe, nhimbe is a strategy of mobilising labour forces in social, economic and political activities. In other words, nhimbe provides villagers with labour force. It actually prompts relatives and neighbours from other villages to participate in the farming and social activities which rotate in a special area from one field to another (Daneel 1971:35). As such, '[e]ven for those who have sufficient means to become economically independent, the nhimbe parties remain of great importance' (Daneel 1971:35).

The gist of nhimbe is that the community collaborates collectively in economic, religious, social and political activities. It can be celebrated with a meal, beer or mild beer (maheu or muchaiwa). This is in contrast to the view of Gukurume (2013), Mudavanhu and Chitsika (2013) and Wrolson (2009:1-129) who hold the view that nhimbe is only a beer party. The beer for nhimbe is announced to the public in advance. Daneel (1971:35) says, ' $[a] s$ such it is an integral part of Shona social life but with distinctly economic implications'. In other words, nhimbe is a way of disaster risk management strategies amongst the Shona. Beer is a promise of economic and social interdependence of farmers who rely mostly on subsistence farming. Nhimbe becomes a certain way of getting communal assistance. In the following sections, the authors briefly explain the concepts of jakwara and jangano which are closely linked to nhimbe.

\section{Equivalents of nhimbe amongst the Shona}

The nhimbe concept has other Shona equivalents. Differences are either dialectical or occasional. ${ }^{2}$ According to Tavuyanago, Mutami and Mbenene (2010:6), 'work parties were of two different, but closely related forms'.

\section{Humwe}

The first of these was humwe [beer work parties]. 'Humwe' was invariably known as hoka, nhimbe or jakwara. In humwe, an individual seeking to get the assistance of others in his or her work brews some beer and prepares some food for the workers. Humwe makes the work process a social event akin to a feast in which the workers rejoice (and make merry) at the same time as they carry out serious work business.

2.The Shona language has various dialects that include Zezuru (Mashonaland West East and Centra provin East and Central provinces), Karanga (Masvingo province), Manyika (Manicaland) and Korekore (Mashonaland West and Central). It is also noted that some occasion assume a different name to nhimbe though essentially, the element of collaborative work is the domineering factor. An example is jakwara which is used for the threshing and winnowing of grains.
Although humwe could be called for other work processes, such as the thatching of huts or fencing of homesteads, it was largely an approach used in the production of grain crops (Tavuyanago, Mutami \& Mbenene 2010:6). Humwe could be called for all the stages in the circle of grain production, from cutting down trees, digging the land, sowing the crops and weeding the crops, to harvesting the crops. According to Bhila (1982), humwe was also called for such work as the threshing of the harvested crops and with the winnowing of the threshed crops.

\section{Majangano}

The second of the work processes in the production of traditional grain crops was majangano [non-beer work parties] (Gombe 1998). Majangano operated as a simple labour exchange programme in which members took to the work of each household in turn without the host having to prepare beer (and in some cases, even food). A generous host could, however, still make some provisions for his or her guests. Although majangano could be used in all the stages of grain production, much like humwe, the work process tended to find favour with the last stages of production involving threshing and winnowing of grains. The two stages marking the end of the farming season required the farmers to remove their crops from the temporary holding places (usually bare rock on which threshing took place) to the more durable granaries before livestock could be allowed to roam freely in the fields during the dry season. Majangano, which did not involve the cumbersome process of preparing beer, thus enabled for speedy removal of crops from insecure temporary holding places to which even thieves could wreak havoc if the crops were not quickly removed to secured places. The two work processes, humwe and majangano, not merely brought people together in the production of food, but also accorded the people the opportunity to socialise on a wide range of issues concerning their society. Bhila (1982) argues that humwes and majanganos, for example, accorded members of the community the opportunity to share jokes and to tease each other at the same time as the people worked. Jokes and teases were all hallmarks of a sharing - and peace-loving society.

\section{Locating nhimbe within the wider African context}

In dealing with this topic, it is noted that nhimbe has its equivalents around Africa. There are hybrid terms that are akin to it. Examples are: Ujamaa of Julius Kambarage Nyerere and Harambee of Mzee Jomo Kenyatta.

\footnotetext{
Ujamaa

Ujamaa is a Kiswahili word for the traditional kinship communalism existing in rural communities in Africa (Boesen et al. 1977:11). The literal translation of the term is familyhood. The argument is that members of the community lived and worked together consciously or unconsciously. This is how life was understood. Ujamaa reinforced each other against difficulties (eds. Minogue \& Moloy 1974:87).
} 
Members of the community thought of themselves as one because of culture and language. The person's identity was established in terms of relationship, this is why sense of belonging is vital amongst the Shona people. Ujamaa produced the sense of joint labour whereby the property belongs to all people. Therefore, Ujamaa is when people live in an organised way without exploiting one another. Thus, people are urged to secure their needs cooperatively. The underlining factor of Ujamaa is the knitting of spirits (Mwoleka \& Healey 1976:9). This concept is about educating people's attitudes in a way that make them brothers and sisters. It is a community where members deliberately organise themselves as living parts of the same organism without exploiting one another. The heavy emphasis of Ujamaa is gradual rural development. In Ujamaa everyone has a corresponding duty to cooperate and contribute for development.

\section{Harambee}

Harambee is attributed to Jomo Kenyatta, which means pulling together or collective effort (Getui 2009:184). Furthermore, Harambee is guided by the principle of collective good and mutual social responsibility. Another feature of Harambee is self-reliance based on grass-root projects that the people identify with. In addition, Kenyatta (1982) said:

It is good to be together, but to be together for a purpose is even better. Our national purpose is to develop the resources of our land so that all our people may lead a happier life. (p. 123)

Harambee is used for economic and social development (Mbithi \& Rasmusson 1977:13). It is self-help that aims to contribute to development. According to Mbithi and Rasmusson (1977:13), 'Harambee as a concept, means collective effort, i.e. pull together'. This concept embodies mutual assistance, joint effort, mutual social responsibility and community self-reliance (Mbithi \& Rasmusson 1977):

It is applied in day-to-day life in such ways as collective neighbourhood house-building, weeding, bush clearing, irrigation, harvesting and fund-raising. The term harambee has its equivalence in their Kenyan tribal languages. It is applied to activities of a village. (p. 13)

The critical issue is to support rural poor people to organise themselves to participate in economic and sustainable development. This ensures equitable share of the benefits. Harambee is a financial support and projects initiation by a family or community.

As alluded to above, the concept of nhimbe implies collaborative ministry that finds resonance in the Shona way of life. Collaboration, as defined by Sofield and Juliano (1987:11), is the identification, release and union of the gifts of all people. The basic assumption is that every person is gifted and called to do something, that is, collaboration. The concept of giftedness is central to an understanding and implementation of collaborative ministry.

\section{Developmental praxis of Nhimbe}

There are several ways of practising nhimbe. The traditional procedure for nhimbe is that the host seeks permission or simply informs the village head or headman of his or her intentions, date and venue to have a nhimbe. This will entail the nature of work to be done. The duration of notice depends on the community; some can notify a week before, whilst others can do it 1 month or 2 weeks before the day of doing the work. As Dhodho (2015:51) observes, '[i]nvitations are also send [sic] out to various village-heads and even the local Headman so that he/she also graces the ceremony'. On the very day of nhimbe, people arrive early in the morning so that they can start working whilst it is cool. All the participants bring their different expertise. These involve collective agricultural activities such as sowing, ploughing, weeding and reaping (Daneel 1971:34). Although a family can work on the land allocated to it, but whenever it is overwhelmed by labour, a nhimbe is organised. During the harvesting period, there is usually nhimbe of cutting zviyo [red millet], sorghum and rapoko in most villages. It is a celebration of nhimbe that brings people together where they work as a community. Almost everyone from around the village comes along to the nhimbe with a knife or a basket to place the millet.

Nhimbe becomes a community ownership. It is a community development and empowerment approach. This is because a community works together. People work together and share proceeds. However, this also should be enhanced with new technical methods of communal empowerment that come with donors and local government. People can work together because of their locality and sense of belonging. As Nzenza (2017:n.p.) states, '[w] e could work together in one big group because we are a community with the same beliefs and values of hard work'.

It is a system whereby one individual calls those within the same community to come and help him or her to sow, plough, weed or harvest. But nhimbe can also include moulding bricks, thatching, fencing and digging and spreading manure in the fields. Hence, Nzenza writes, at nhimbe '[e]ach person brought a working tool and the owner of nhimbe provided food and drink'. Normally on this occasion, people enjoy the privilege of eating meat and drinking which are difficult to get in rural areas.

The widows, orphans and the aged without labour and source of income would benefit from nhimbe and the chief benefits immensely. Nhimbe would assist the poor in the society. As Mawere and Awuah-Nyamekye (2015) argue:

The communalistic nature of the Shona society embedded within their ethical and societal values and mores enabled them to see to it that the welfare and plight of the disadvantaged and vulnerable members were promoted and looked after by the entire community. (p. 1)

The Shona community catered for the less privileged through nhimbe. This was a social security mechanism to support the landless, orphans, the old and widows. For 
agricultural purposes, nhimbe is called at the beginning of the rainy season. People assist others with ploughing and weeding the fields. However, ' $[t]$ he heavy work on the fields must be done by men' (Bourdillon 1976:73). The heavy work includes clearing of a field, cutting small trees, digging manure and moulding bricks. But, women can also partake in planting, weeding, reaping and threshing. Generally, women do not take up strenuous tasks. This attracts people from the whole community who come with working tools. Even people without any of the required tools just come and assist those with them. As Dhodho (2015:50) states, '[ $t]$ hese activities are characterized by equal partnership and taskorientation; no one looks at the sophistication of another's equipment, all is required is execution of the task at hand'. Thus, no one can fail to provide something. A person without cattle, plough or hoe can provide an axe to cut down trees or even relieve the old men. This means that any failure to cooperate during this period renders one a social misfit. Amongst the Shona, such a person is dead. In addition, participation in the nhimbe system is a matter of social urgency because anyone who for one reason or another keeps himself or herself and the family away from this activity is cut off from communal life.

Just in the same thought of Nzenza, on the day of nhimbe, men and women start very early in the morning to do work like ploughing in the fields, harvesting, digging manure, moulding bricks or fencing. When it is around 10:00 or 11:00, people are served with something to drink. After working for about almost $3 \mathrm{~h}$, people go for a short break called chikumura mambhachi. The participants are served with breakfast which is usually in the form of light beer (muchaiwa) or mageu. In this contemporary period, people can have tea, home-made bread (chimupoto chwai), sweet potatoes or maize. This is called chikumura mabhachi or chirovamatsa [traditional tea break]. It is presumed that people have worked and need to be re-energised. Mostly, young people either drink something non-alcoholic but elders can take a sizeable quantity of beer. The moral principle is that people should not get drunk early until they finish the work to be done.

But later people can drink to their fill in order for them to work harder. After breakfast, people are expected to work again before they are served with lunch (Dhodho 2015:52). Lunch is usually served with sadza, rice, meat and traditional beer. If the host can afford other luxuries, he or she can give out to the participants. Beer is served at intervals. Dhodho (2015:52) states, '[i]t is after beer has been served that participants can start singing relevant songs'. Some of the songs teach or reprimand immoral behaviour. Chiwome (1992) and Wrolson (2009) add that such songs and their messages could not be repeated in any other social setting and neither could that be taken to implicate any person involved in immoral activities. This is confirmed by Mudavanhu and Chitsika (2013) who argue that as people work they are served with beer. This makes them work the whole day without realising the amount of time they have spent working. This is affirmed by Daneel (1971) who argues:

Much beer (doro) is brewed for the occasion, because beer is a tangible form of compensation (not as payment in the strict sense of the word, but in recognition of the principle of reciprocity) given to the village members who offer their services on the appointed day. (p. 35)

Hence, beer brewed for nhimbe is a symbol of economic and social interdependence. It is a reliable way of obtaining the required assistance at the rightful moment. This is why a person who wilfully fails to participate in nhimbe is considered a social misfit.

In other instances, people eat and drink at lunchtime. When people get drunk, they even ask for more work to be done. When people are excited, this is accompanied by dancing and singing. Wrolson (2009) argues that traditionally participants are urged to sing out any immoral denunciations but they should not show anger against anyone. As people work, they sing so that they are motivated to work and complete the task easily. 'The songs also assisted to synchronize the movement of whatever tools so that participants kept the same tempo and pace' (Dhodho 2015:51). This can go on until evening. Some people would have their supper and sleep at the same place. It is an occasion of celebrating good community work. The nhimbe becomes an occasion for people to meet and discuss. It is therefore understandable that membership of Christian church that strictly forbids any form of beer drinking would, if taken seriously by a villager, have far-reaching social and economic implications for itself. There is a mistaken notion amongst some believers that nhimbe beer is associated with ancestral spirits and evil deeds. In order to avoid economic implications, these types of churches have allowed their members to prepare mangisi [unmalted sweet beer] so that they can get labour force. But sometimes this can make people get drunk if it has been kept for a long time before it is drunk. At times, elders do not go to such a nhimbe and send youngsters. In addition, another nhimbe would be announced before people depart.

Nhimbe is organised in such a way that it does not collide with the traditional Sabbath (chisi) or Sunday. Usually, these two days are reserved for people to pray and attend meetings. Thus, people honour the ancestors and God so that they continue to receive good rains and enjoy good harvest. This is the common practice since most people have become Christians.

After harvesting, people engage in the form of nhimbe called jakwara. This is done during the dry season. It is when people perform threshing and winnowing rapoko, millet or sorghum. (Jangano: Taking turns to look after livestock) Nzenza (2017:n.p.) opines, '[d]uring the jakwara ceremony, the vakuwasha or sons-in-law, went out into the bush to find thin long sticks, mupuro from the mutondo trees'. However, these can also be cut from any tree depending on the locality or 
availability of trees. But there are some sacred trees that cannot be cut or pruned. On this occasion, women bring winnowing baskets. All the millet or sorghum is placed on the flat hard rock wherein they are thrashed either by cattle or later finished by men. Women support men by ululating and singing to thrash thoroughly. Nzenza (2017) stipulates that some village secrets are shared through the medium of the song.

Based on the above sensitivity, children are not allowed to attend jakwara. This is because adults see this occasion as the forum to voice out old grievances. They tell some secrets and make sexual references to an incident of adultery. Jakwara is a moral occasion to reprimand one another. According to Nzenza (2017:n.p.), '[t]he adults danced, laughed and spoke with much laughter'. Like a seal of confession, the secrets shared remain at jakwara. Thus, to share something of jakwara is tantamount to being immoral and the person even deserves to be severely punished or excommunicated from society.

\section{Developmental outcomes of nhimbe}

\section{Nhimbe guarantees community development}

The solution to the problem of development requires cooperation amongst individual communities. Individuals condition one another and can affirm that everyone can succeed in development. It develops the integral person. The Shona people are committed to the nhimbe. This enhances people to engage in developmental activities that change their life situation. People wish each one to succeed in his or her project. Nhimbe is a community activity. For instance, in agriculture, nhimbe ensured good farmers to have sufficient food for their needs and the society. It was a skilful way of preparing for impeding droughts by successfully producing enough food. Nhimbe provides techniques to store grains so that nothing is put to waste. In other words, it cushions the impacts of natural disaster and possible starvation. Moreover, nhimbe makes people increase their production and trade their surplus (Beach 1995:41). The collective capacity to respond and engage influences others to change attitude. Thus, people are united and share life experiences within the same area. People of the same community participate in nhimbe. The intended result is for economic, social and political development.

Because communities have many resources within and outside, they can engage people to respond to develop themselves. The resources that exist in the culture of people can bring change if people work when united. An individual does not solve the challenges.

Nhimbe participation tends to result in the mobilisation of resources and accomplishment of more tasks with the same or less budget. This enhances efficiency in resource use for development. Moreover, nhimbe enhances self-reliance and development in an area. The culture to work and skills bring holistic personal transformation. In addition, the system of nhimbe strengthens the social, religious and moral fibre of the community because relatives and neighbours have time to participate in different activities. According to Daneel (1971:35), ‘[e]ven for those who have sufficient means to become economically independent, the nhimbe parties remain of great social importance'. Thus, nhimbe is an occasion when people meet in large numbers to make work easier.

\section{Education}

Education is highly valued amongst the Shona. This is regarded as a solution to get rid of poverty. Hence, people respect people who are educated. Education is not an individual effort but of community. It is the responsibility of the community that children go to school. The community supports those who are lacking resources through donations. This is a form of nhimbe. Thus, nhimbe teaches people to have a sense of community. The place and dignity of an individual are benchmarked by one's contribution to the community. Thus, a person has to be sensitive to the needs of others in the community. The Catholic Social Teaching of the Catholic Church (CST) No. 376 states:

Faced with the rapid advancement of technological and economic progress, and with the equally rapid transformation of the processes of production and consumption, the Magisterium senses the need to propose a great deal of educational and cultural formation. (n.p.)

Thus, a great deal of educational and cultural work is highly important. This includes the role of education in preparing responsible citizens. This should bring out the sense of responsibility amongst people when consuming information and substances. Education forms a person in the fullness of human dignity in the image of God.

\section{Economy}

In Zimbabwe, foreign-owned industries have collapsed. As a result, many people have been left unemployed. Even the agricultural production has been affected adversely. De facto, since the implementation of land reform in 2000, agricultural production has decreased by $52 \%$ (Stevenson 2008). Currently, the country suffers from cash crisis. Hence, employees cannot receive salaries, pay school fees or medical costs. In this economic environment, the nhimbe approach is needed to resuscitate the economy. The black and white farmers should collaborate in farming skills. Moreover, the local community should protect their resources and thereby shun greedy technocrats who move from one province to other for plundering resources. For instance, in Marange, diamonds worth more than $\$ 2$ billion went missing (Chiketo 2013).

\section{Housing}

Shelter is a necessity. The homeless orphans and the elderly people should have access to houses or stands offered by the government. It is high time people own houses and not rent. People can assist each other in moulding bricks and clearing ground. In addition, people should have access to 
electricity, toilets and clean water. The disposal of garbage should be done in a way that is not hazardous to health. Resources can be used to build houses for the homeless affected by floods.

The community leader who chooses nhimbe approach in executing his or her duties becomes effective. The assumption is that shared responsibility and collaborative ministry serve as a foundation for the efforts to advance development in the world (Hubbard 1998:20). Nhimbe is the centre of community life.

Thus, a Christian community serves by using talents. In other words, people exercise different roles in developing their standards of living. Therefore, every person's contribution is vitally needed in order to build up the community. Hence, collaborative ministry is neither a luxury nor an option. It is rather a necessary dimension of community life. According to Hubbard (1998:25), ' [i]t demands interdependence and partnership ...' People work as a family without distinctions of roles.

\section{Conclusion}

In this article, we have seen that nhimbe is a value that empowers people. It is manifested in engaging communities to sustain themselves economically, socially and politically. The individual effort is supported that it can be realised. It gives a person a sense of the community. Both community and individual problems are approached and solved as our own. The talents of individuals are identified and cultivated.

Moreover, nhimbe is a mechanism used to manage natural calamities like drought and famine (Mawere \& AwuahNyamekye 2015):

The communalistic nature of the Shona society embedded within their ethical and societal values and mores enabled them to see to it that the welfare and plight of the disadvantaged and vulnerable members were promoted and looked after by the entire community. (p. 1)

The traditional Shona society catered for the orphans, the widowed and those who were visually and physically challenged. Such benevolent measures ensured that nobody goes hungry and homeless. Thus, people have compassion for others in need shown by caring acts of generosity or kindness. Nhimbe shows the communal leadership style. Thus, a good leader would encourage the community to show sympathy to the landless, hungry and the homeless. It is important to note that nhimbe is a social security mechanism, which supports the disadvantaged and vulnerable community members in the face of potential risks.

To suggest that nhimbe is a viable sustainable development instrument is not an appeal to a fossil culture that is retrogressive. As argued by August (2010), there is something that traditional values, practices and institutions can offer today and in the future. It acknowledges that individual efforts have serious limitations and it is only a recognition of the giftedness of the other that the effort to collectively progress as a society is realised. This progress can be socioeconomic, political and religious.

\section{Acknowledgements}

This work has been possible through the assistance of Prof. David Kaulem.

\section{Competing interests}

The authors declare that they have no financial or personal relationships that may have inappropriately influenced them in writing this article.

\section{Authors' contributions}

T.M. and P.M. contributed equally to the writing of the article.

\section{Ethical considerations}

This article followed all ethical standards for research without direct contact with human or animal subjects.

\section{Funding information}

This research received no specific grant from any funding agency in the public, commercial or not-for-profit sectors.

\section{Data availability}

Data sharing is not applicable to this article as no new data were created or analysed in this study.

\section{Disclaimer}

The views and opinions expressed in this article are those of the authors and do not necessarily reflect the official policy or position of any affiliated agency of the authors.

\section{References}

Beach, D.N., 1995, Zimbabwe before 1900, Mambo Press, Gweru.

Bhila, H.H.K, 1982, Trade and politics in a Shona kingdom: The Manyika and their Portuguese and African neighbours, 1575-1902 (Studies in Zimbabwean History), Longman, Harlow.

Boesen, J., Storgaard Madsen, B. \& moody, T., 1977, Ujamaa - socialism from above, Scandinavian Institute of African Studies, Uppsala.

Bourdillon, M.F., 1976, The Shona peoples, Mambo Press, Gwelo.

Catholic Church, 1995, Catechism of the Catholic Church, Doubleday and Company, New York, NY.

Catholic Church, 2004, Compendium of the social doctrine of the Church, Paulines Publications, Nairobi.

Chiketo, B., 2013, 'Zimbabwe: Marange diamonds - Zanu-PF's best friend?' viewed n.d. from http://www.minesandcommunities.org/article.php?a=12136, http:// thinkafricapress.com/zimbabwe/diamonds-marange-zanu-pfs-best-friend.

Chiwome, E.M., 1992, 'Traditional Shona poetry and mental health', Zambezia 19(1). https://hdl.handle.net/10520/AJA03790622_230.

Daneel, M.L., 1971, Old and new in Southern Shona Independent Churches, vol. 1, Mouton and Company, The Hague.

Dhodho, M., 2015, Médecins Sans Frontières, Southern Africa Medical Unit, Cape Town. 
Getui, M., 2009, The ethnicity factor in politics and religion, Pauline Publications, Nairobi.

Gombe, J.M., 1998, Tsika DzaVashona, College Press, Harare.

Gukurume, S., 2013, 'Climate change, variability and sustainable agriculture in Zimbabwe's rural communities', Russian Journal of Agricultural and Socio-Economic Sciences 2(2), 89-100.

Hubbard, E.J., 1998, Fulfilling the vision, The Crossroad Publishing Company, New York, NY.

Kenyatta, J., 1982, War, land and politics in Kenya, Palgrave Macmillan, New York, NY.

Mawere, M. \& Awuah-Nyamekye, S., 2015, Harnessing cultural capital for sustainability: A Pan Africanist perspective, Langaa Research and Publishing CIG, Mankon.

Mbithi, P. \& Rasmusson, R., 1977, Self-reliance in Kenya: The case of Harambee, The Scandinavian Institute of African Studies, Uppsala.

Minogue, M. \& Moloy, J. (eds.), 1974, African aims and attitudes, Cambridge University Press, Cambridge, MA.

Mudavanhu, C. \& Chitsika, T., 2013, 'Coping with and adapting to food shortages and adversities in semi-arid regions of Zimbabwe: The case of Chivi District', International Journal of Innovative Environmental Studies Research 1(2), 27-30.
Murisa, T., 2013, 'Social organization in the aftermath of fast track: Analysis of emerging forms of local authority, platforms of mobilization and local cooperation', in Land and agrarian reform in Zimbabwe: Beyond white-settler capitalism, pp. 251-290, $\mathrm{S}$ and $\mathrm{S}$ Pub.

Mwoleka, C. \& Healey, J., 1976, Ujamaa and Christian communities, Gaba Publications, Eldotret.

Nzenza, S., 2017, 'Celebrating Nhimbe, our traditional communal way of working together', The Herald, 31 May, ANZ Publishers, Harare.

Sofield, L. \& Juliano, C., 1987, Collaborative ministry, Ave Maria Press, Notre Dame, IN.

Stevenson, T., 2008, 'Zimbabwe: Background', EveryCRSReport.com, viewed 19 December 2020, from https://www.everycrsreport.com/reports/RL32723.html.

Tavuyanago, B., Mutami, B. \& Mbenene, K., 2010, 'Traditional grain crops in pre-colonial and colonial Zimbabwe: A factor for food security and social cohesion among the Shona people', Journal of Sustainable Development in Africa 12(6), 1-8.

Vianni, W., 2016, 'Jomo Kenyatta: War, land, and politics in Kenya', in E. Obadare \& W. Adebanwi (eds.), Governance and the crisis of rule in contemporary Africa, African Histories and Modernities, Palgrave Macmillan, New York, NY.

Wrolson, J.L., 2009, 'Re-inventing memory and reforming performances: A genealogy of panic theatre in Zimbabwe', PhD thesis, University of Kansas. 